\title{
XXXV. On the biniodide of mercury
}

\section{Robert Warington Esq.}

To cite this article: Robert Warington Esq. (1843) XXXV. On the biniodide of mercury , Philosophical Magazine Series 3, 22:144, 209-212, DOI: 10.1080/14786444308636354

To link to this article: http://dx.doi.org/10.1080/14786444308636354

册 Published online: 01 Jun 2009.

Submit your article to this journal 준

Џ Article views: 2

Q View related articles ¿ 
the dampness of the weather, a singular difference occurred between two needles, one of which was of brass and the other magnetic, and both of them five-eighths of an inch in length. The brass one invariably placed itself at right angles, while the magnet remained uninfluenced, though it was the more delicate of the two, as it had an agate socket. This fact, as well as what $I$ have just stated of the other magnetic needle, showed that there was a struggle between the polarity of the needle and the influence of the electric current. It was observed that whenever there was a powerful stream of electricity employed, it was seen to escape in a beautiful pencil of light from the point of the other end of the wire which was kept coiled up and unemployed. The machine used in these experiments is of the plate construction and eighteen inches in diameter, but is at present in very indifferent working order.

M. Becquerel mentions in his History of Electricity that he thought he had made needles of various substances move in a galvanometer when under the influence of a voltaic current, but that he afterwards found that the slight movements he had observed were owing to currents of air occasioned by the heat evolved. The present experiments, however, are so decisive and unequivocal that they cannot be attributed to such a cause; still my own convictions are, that they are not dependent upon magnetic influence.

January 31, 1843.

$$
\text { I am, Sir, \&c., }
$$

Graves C. Haughton.

XXXV. On the Biniodide of Mercury. By RoBerT

Warington, Esq., Secretary to the Chemical Society. \&c.

\section{To the Editors of the Philosophical Magazine and Journal. Gentlemen,}

I SHALL feel obliged by your inserting in an early Num1 ber of your Journal the following observations in reply to a letter on this subject by Mr. Fox Talbot, which appeared in the Number of the Philosophical Magazine for November 1842 (page 336); at the same time I cannot help regretting that your pages should be occupied by a matter of personal discussion; but as it would appear, from the contents of the letter in question, that I had, either ignorantly or wilfully, made use of the published observations of another, and as Mr. Talbot pointedly "begs to draw my attention" to the question of his priority to the "discovery of one of the most curious phænomena in optics," it obliges me to adopt the same public channel of reply for the purpose of clearing my-

Phil. Mag. S. 3. Vol.22. No. 144. March 1843. P 
self from the implications contained in his letter. Had my time permitted I should have replied to this charge at an earlier date, but professional engagements have rendered this delay unavoidable.

In the communication read before the Chemical Society on February 1, 1842, and afterwards inserted in your Journal of September of the same year, I do not lay any claim to the discovery of many of the phænomena therein detailed; nay more, it is distinctly stated (p. 193), "The resumption of the scarlet colour (in the sublimed yellow crystals of the biniodide) has been attributed to an alteration in the molecular arrangement of the crystals, and it was with the view of clearly ascertaining this point that the follorwing microscopic investigations were undertaken." I am at a loss to imagine how this can be construed into any wish on my part to deprive Mr. Talbot of what he claims as his discovery. But we must proceed to examine this matter with more care. In 1830 the alleged discovery of $\mathrm{Mr}$. Talbot of 1836 was shown me by Mr. J.T.Cooper, with whom I was then assistant, and in the same year the phænomena claimed were exhibited as class-room illustrations; however, we must go even further back to the original paper on the subject by $M$. A. Hayes, and which was published in the American Journal of Science and Arts for 1829, vol. xvi. p. 174. This paper was republished in the Quarterly Journal of Science of the Royal Institution for 1830, p. 208; and it was noticed in the Paris edition of Berzelius's Traité de Chémie of 1830. Irrespective of these facts, the observations made by $\mathrm{M}$. A. Hayes are so exactly those claimed by $\mathrm{Mr}$. 'Talbot in his November paper, that I feel bound to place them in juxtaposition.

Mr. Fox Talbot, 1836.

"In that memoir (Phil. Mag., 1836, S. 3. vol. ix. p. 1.) I have shown,-

" lst. That when iodide of mercury is sublimed between two plates of glass nearly in contact with each other, it cools in the form of thin rhombic plates of a pale yellow colour.

" 2 nd. These often retain their colour when cold, if left undisturbed.

"3rd. But if such a crystal is disturbed, as for example, by touching it with a needle at any
M. A. Hayes, 1829.

"If the precipitate, obtained as above, by the addition of iodide of iron in solution to one of bichloride of mercury, be heated in a small subliming apparatus, or in a glass tube, it melts and sublimes copiously, and the vapour is condensed in large transparent rhombic plates, of a fine sulphur yellow colour.

"These crystals are permanent in the air and unaltered by the direct solar rays ; but the slightest friction or the contact of a fine point, is sufficient to alter their interior arrangement. The point 
point of its surface, it instantly turns scarlet at the point touched, and the scarlet colour is rapidly propagated over the whole crystal.

" 4 th. The crystal moves, and is spontaneously agitated during the time it is changing colour.

" 6 th. I added that I thought this phrenomenon the most evident proof we yet possessed of the dependency of colour upon internal molecular arrangement." of contact instantly becomes of a rich scarlet, and the same colour spreads over the whole surface of a single crystal, and extends to the most remote angle, if a group of crystals be the subject of experiment.

"This change of colour is accompanied by a sensible mechanical motion, so that a small heap of the crystals appears as if animated, affording an elegant illustration of the connexion between colour and the mechanical structure of bodies."

A comparison of the above extracts will doubtless entirely alter Mr. Talbot's opinion as to these points of his claims to originality in regard to the observations of 1836.

I must now turn to the printed paper in the 9th vol. (S. 3.) of the Philosophical Magazine, p. 2. Mr. Talbot there admits " that chemical writers have observed" these "changes of colour," quotes Dr. Inglis's authority for the retention of the yellow tint for a considerable time, and states, that " wishing to examine into the cause of these facts" he instituted certain experiments, which are then detailed; so, that independent of the above paper in 1829, of M.A. Hayes, Mr. Talbot proves in this very paper of 1836 , that Nos. 1,2 , and 3 of the points claimed in 1842 to have been "sufficiently established" by him in 1836 had been previously observed. The next point has reference to the first part of the claim No. 6. In $1836 \mathrm{Mr}$. Talbot states that "the change of colour is accompanied by a visible internal motion in the crystal, like a sinking or giving way of successive ranks of particles." Here is not a syllable about lamince which he has now laid claim to, and which term I consider implies a very different effect from either "ranks of particles" or "rows of molecules:" it is used in my paper to represent the plates of the crystal. Again, as to the commencement of the change of colour taking place "by the appearance of a red streak along one of its sides or edges," and " the boundary of the red and yellow" being "a straight line parallel to troo sides of the rhomboid," and that " its motion is across the crystal from one of these sides to the opposite one;" on these points I cannot agree with Mr. Talbot; and he will perceive in $A$, fig. $1, c, d$ and $e$, fig. 2 , of my own paper, that the very reverse is shown, by drawings taken directly from the field of the microscope by the camera lucida; so that 
his claim No. 5 is incorrect. With respect to the claim No. 7, my observations regarding the effects of polarized light apply to the last set of experiments on the precipitated iodide while suspended in the mixed solutions, and therefore Mr. Talbot's remarks, referring as they do to the sublimed crystals, cannot in the slightest degree interfere with them. As to the quoted expression, "the field of view appears scattered with the most brilliant assemblages of (rubies, topazes, emeralds and other) highly coloured gems," \&c., the names of which, inclosed in the parenthesis, have, inadvertently I presume, been omitted in the quotation, the only similar word that $I$ can find which occurs in my own description of these appearances is the word 'gems,' and if the use of that expression, applied as it is to the precipitated biniodide of mercury, is to be considered as implying a piracy on Mr. Talbot's application of it in viewing the crystals of sulphate of copper by polarized light, I can only plead the poverty of the English language, as I had never seen Mr. Talbot's paper (Phil. Mag. vol. v. p. 324) until he publicly drew my attention to it.

In the concluding paragraph of $\mathrm{Mr}$. Talbot's letter he first states that "the second part of my paper, however, contains a fact both new and important," and then immediately afterwards proves that it is not new at all, for that he described in 1836 a phænomenon of the same kind previously unexampled, and that this is only a second example. Now surely these statements are perfectly contradictory. Observed facts cannot be new and old. But let us examine in what respects these phænomena are alike. Mr. Talbot takes iodide of lead, prepared through the medium of the acetate of that metal and iodide of potassium, while fresh, he does not say whether it was washed to remove the acetate of potash or not, and warms it over a spirit-lamp, when certain beautiful changes are observed. My own observations are on the precipitated biniodide of mercury, which is known to be first precipitated yellow, then gradually to deepen in tint, and ultimately to become scarlet; under the microscope the first precipitate is in minute crystals of the rhombic form, similar to the yellow sublimed salt, and these slowly and spontaneously become disintegrated, dissolve and are replaced by the octohedron with the square base like those obtained by the more cautious sublimation. I am at a loss to imagine where the similarity between them exists. It would take up too much space to go further into this matter, and I must content myself with leaving it to the study of any of your readers who may wish further to analyse this subject. A gain apologizing for thus occupying so much room in your Journal, I remain, Gentlemen, Yours, \&c., Apothecaries' Hall, Feb. 10, 1843.

Robert Warington. 